\title{
Periodontitis Prevalence and Severity in Adults: A Cross-Sectional Study in Norwegian Circumpolar Communities
}

Gro Eirin Holde, ${ }^{* \dagger}$ Nils Oscarson, ${ }^{*+}$ Tordis A. Trovik, ${ }^{\ddagger}$ Anders Tillberg, ${ }^{* \dagger}$ Birgitta Jönsson ${ }^{* \S}$

* The Public Dental Health Service Competence Centre of Northern Norway, Troms $\varnothing$, Norway

† Department of Clinical Dentistry, Faculty of Health Sciences, UiT the Arctic University of Norway, Tromsø, Norway

‡ Department of Community Medicine, Faculty of Health Sciences, UiT the Arctic University of Norway, Troms $\varnothing$, Norway

$\S$ School of Education, Health and Social Studies, Dalarna University, Falun, Sweden.

\section{Correspondence address:}

Gro Eirin Holde

Institute of Clinical Dentistry, Faculty of Health Sciences, UiT the Arctic University of Norway

PO Box 2406

N-9271 Tromsø, Norway

Tel.: +47776 49115

E-mail: gro.e.holde@uit.no

Word count: 3917

Figures: 2

Tables: 4

References: 48

Running title: Periodontitis Prevalence and Severity

Key findings: Periodontitis affected half of the examined population with a varying distribution across sociodemographic and behavioral variables. 


\section{Abstract}

Background: The aim of this study was to describe the prevalence, severity and extent of periodontitis in the adult population of circumpolar communities in Norway using data from the study Tromstannen - Oral Health in Northern Norway.

Methods: In this cross-sectional survey, data were collected from a randomized population sample (20-79 years) in Northern Norway. Periodontal conditions were assessed for 1,911 dentate adults with a full-mouth periodontal examination. Probing depth (PD) and bleeding on probing (BoP) were measured at six sites per tooth. Radiographic bone loss (BL) was examined using orthopantomograms.

Results: According to the CDC/AAP case definition, $49.5 \%$ of participants had periodontitis and $9.1 \%$ had severe periodontitis. Periodontitis prevalence and severity increased with age. The extent of BL and $\mathrm{PD} \geq 4 \mathrm{~mm}$ also increased with age, but more rapidly and to a greater extent for $\mathrm{BL}$. The prevalence of periodontitis was higher among men and varied between urban and rural areas. Periodontitis prevalence was positively associated with smoking, lower levels of education and income.

Conclusions: This study reveals a high burden of periodontitis among adults living in circumpolar communities in Norway. The results showed sociodemographic disparities regarding periodontitis, and highlights the importance of further investigation of factors influencing periodontal health.

Keywords: epidemiology; periodontal diseases; dental health surveys; arctic regions 


\section{Introduction}

Periodontitis is a common disease among adults; its prevalence is reported by European and US studies to range from $31 \%$ to $76 \%{ }^{1-6}$ Severe forms of the disease affect $11 \%$ of the global population. ${ }^{7}$ Differences in demographic characteristics and levels of exposure to various risk factors between different populations can partly explain the wide range in the prevalence of periodontal disease, but this variance can also be the result of differences in periodontal examination protocols and case definitions between studies using different measures of periodontitis. ${ }^{8-11}$ To enable a comparison between populations, the Joint EU/USA Periodontal Epidemiology Working Group has proposed standards for reporting the prevalence and severity of chronic periodontitis. ${ }^{12}$

Periodontal disease is considered a major public health problem. ${ }^{13}$ It is reported to have a negative impact on oral health-related quality of life and patients' lives, including impairment, functional limitations, discomfort and disability. ${ }^{14-16}$ Consequently, it is important to gain knowledge about a population's periodontal conditions, and by collecting reliable and comparable periodontal data, researchers can contribute to global estimates of the burden of periodontitis. ${ }^{7}$

Knowledge about the prevalence of periodontal disease in the general adult population of Norway has been lacking. A nearly 40 years old study (1979) described periodontal conditions in a coastal community in Northern Norway ( $\mathrm{n}=297$, aged 20-69 years). ${ }^{17}$ Other studies have described periodontal conditions exclusively in age cohorts (35-year-olds) in Oslo between 1973-2003 ( $n=543$ ) and in a national random sample $(n=394)$ of elderly pensioners. ${ }^{18,19}$ Northern Norway has a history of low dentist-to-patient ratio, and in a national health interview survey of living conditions, it was reported that Northern Norway had the poorest self-reported dental health and the least frequent use of dental health services. ${ }^{20}$ Additionally, large geographic disparities with respect to tooth loss and denture wearing have been reported in Norway. ${ }^{21}$ There is a need for studies estimating the burden of periodontitis and possible risk factors in the northern part of the country to aid the planning of dental health care services in the region. Furthermore, knowledge of periodontal 
conditions in these northern communities could be of interest for other regions with similar living conditions, as there are few studies describing periodontal conditions. ${ }^{2,5,22-26}$ Studies of periodontitis prevalence in circumpolar countries provide only national estimates or estimates from regions south of the Arctic Circle, ${ }^{2,5,22-24}$ or they focus on indigenous populations. ${ }^{25,26}$ This is the first epidemiological study in the general adult population of an entire Norwegian county. The aim was to describe the prevalence, severity and extent of periodontitis in circumpolar communities in Norway, according to the recommended standards for presenting chronic periodontitis, ${ }^{12}$ as well as to examine differences in the sociodemographic and behavioral characteristics of people with periodontitis.

\section{Materials and methods}

\section{Study design and data collection}

To describe periodontal conditions, data from a dental health survey in Northern Norway (Tromstannen - Oral Health in Northern Norway, TOHNN) were used. ${ }^{27}$ The TOHNN study is a population-based cross-sectional representative study, with a target population of adults aged 20-79 years, living in Troms County, Norway. Troms County is one of three Norwegian counties located north of the Arctic Circle. Troms $\varnothing$, one of the largest cities within the Arctic Circle, surrounded by islands, fjords and mountain peaks, and the gateway to the Polar Seas, is included in the catchment area. In January $2013,112,253$ people in the selected age group inhabited the county. A power calculation, with a $95 \%$ confidence interval with a margin of error of $1.5 \%$, indicated that we needed to examine 1,516 individuals to be able to describe the prevalence of severe periodontitis when hypothesizing a $10 \%$ prevalence as reported in the literature. ${ }^{7}$ The total sample $(n=3,000)$ was based on a $50 \%$ attendance rate experienced in other epidemiological studies in Norway. ${ }^{18,28-30}$ To obtain a representative selection of all regions in the county, the sample was stratified on three different areas: Troms $\varnothing(51,110$ people: $46 \%)$, Southern Troms County (49,740 people: $44 \%)$ and northern Troms County (11,403 people: 10\%). 3,000 individuals were randomly selected by simple random 
sampling technique from the population register by Statistics Norway, resulting in 1,380 people from Troms $\varnothing, 1,320$ people from Southern Troms County and 300 people from Northern Troms County. A total of 2,909 individuals were invited to participate in the study by a letter of invitation. Initial non-responders were contacted with an additional letter. Details of the invitation procedure have been described previously. ${ }^{27}$ The study included a questionnaire and a clinical dental examination, and was completed by 1,986 (68.3\%) participants. The study was approved by the Regional Committees for Medical and Health Research Ethics, Norway (2013/348/REC North). All participants provided written informed consent.

Information on sociodemographic characteristics, behaviors and co-morbidities were collected by self-reported questionnaire. The questionnaire covered questions about self-perceived ethnicity, education, annual household gross income (analyzed in three categories according to the national tertiles of gross household income in 2013), diabetes, tooth-brushing frequency, frequency of dental visits, smoking and Swedish type, low-nitrosamine, smokeless tobacco (snus) use. Smoking was assessed with three questions: 1) "Do you smoke on a daily basis?" 2) "How many cigarettes do you smoke each day?" and 3) For how many years have you been smoking?". Number of years of past smoking was also registered. Use of snus was assessed with the same questions. Age was stratified in categories $20-34,35-44,45-54,55-64$ and $65-79$ years. To assess urban-rural disparities, municipalities were categorized into the following three groups: the municipality with the largest city (Troms $\varnothing$ ) was classified as urban; two municipalities (Harstad and Lenvik) with smaller towns were classified as suburban; and the remaining municipalities without towns were classified as rural.

Periodontal examinations were performed on all individuals with natural teeth. Twenty-two participants were excluded because of incomplete periodontal examinations, and $51(2.6 \%)$ were identified as edentulous; two participants had only one tooth and were excluded because of case definition criteria of measurements from two or more teeth. This resulted in 1,911 participants with complete periodontal examinations (Figure 1). Examinations were performed in a dental office by 11 
calibrated dentists assisted by dental nurses. Bleeding on probing (BOP) and periodontal pocket depth (PD) were assessed at six sites per tooth for all teeth. Third molars and implants were excluded from the analysis. Periodontal pocket depth was measured to the closest millimeter with a periodontal probe with single millimeter graduations." Orthopantomograms (OPG) were used to assess the radiographic bone level. ${ }^{2,18}$ Marginal bone levels of both distal and mesial surfaces of all teeth, excluding third molars, were measured linearly with a transparent plastic ruler. ${ }^{31}$ The alveolar bone level was measured in relation to the radiographic apex. The cemento-enamel junction (CEJ), alveolar crest (AC) and radiographically depicted root apex were used as reference points. If the CEJ was destroyed after restorative therapy, the apical margin of the restoration was used as a reference point. The AC was considered the most coronal point at which the periodontal ligament space had a constant width. If the CEJ or AC could not be determined for more than $20 \%$ of the teeth, the participant was excluded from the analysis. Bone loss (BL) was considered present at sites in which the distance from the CEJ to the AC exceeded $2 \mathrm{~mm}$ and was categorized in $10 \%$ intervals as $1-10$, as described by Skudutyte-Rysstad et al. ${ }^{27}$ A modified plaque index was used, ${ }^{32}$ recording plaque at four sites per tooth as present or not using a mouth mirror and periodontal probe.

\section{Periodontal case definition and periodontal parameters}

To estimate of the prevalence and severity of periodontitis, a categorical case definition was necessary. The Joint EU/USA Periodontal Epidemiology Working Group has suggested Centers for Disease Control and Prevention/American Academy of Periodontology (CDC/AAP) case definitions for reporting of periodontitis in epidemiologic studies. ${ }^{12}$ These case definitions are based on PD and clinical attachment level (CAL) with the following definitions: Severe periodontitis: $\geq 2$ interproximal sites with $\geq 6 \mathrm{~mm} \mathrm{CAL}$ (not on the same tooth) and $\geq 1$ interproximal site(s) with $\geq 5 \mathrm{~mm} P \mathrm{PD}$; Moderate periodontitis: $\geq 2$ interproximal sites with $\geq 4 \mathrm{~mm} \mathrm{CAL}$ (not on the same tooth) or $\geq 2$ interproximal sites with PD $\geq 5 \mathrm{~mm}$ (not on the same tooth); and mild periodontitis: $\geq 2$ interproximal sites with $\geq 3 \mathrm{~mm} \mathrm{CAL}$ and $\geq 2$ interproximal sites with $\geq 4 \mathrm{~mm}$ PD (not on the same tooth) or 1 interproximal site with $\geq 5 \mathrm{~mm}$ PPD. In this study, CAL was unknown. To be able to define 
periodontitis according to the CDC/AAP case definition in our sample, the relationship between radiographic $B L$ and CAL was inferred from results in a complementary sample. To get a wide range of attachment levels, 8 patients visiting the periodontal clinic at the Public Dental Health Service Competence Centre of Northern Norway were examined, along with 11 patients with no or mild periodontitis (by first author, GEH). PD and CAL were measured clinically on all proximal surfaces ( $n=786)$, and proximal bone levels on OPGs were recorded. BL was measured as a proportion of the root, categorized in $10 \%$ intervals, $1-10$. The CAL was measured in $\mathrm{mm}$ indirectly by first measuring the PD (= distance from the gingival margin (GM) to the bottom of the pocket), followed by measuring the distance from the CEJ to the GM. If the GM was coronal to the CEJ, the measurement was given a negative value and subtracted from the PD measurement. To assess the ability of measured radiographic bone loss to predict measured CAL, the following model was tested by linear regression:

$$
C A L=\beta_{0}+\beta_{1} \cdot B L
$$

In this formula, $\beta_{0}$ was the intercept and the value for $C A L$ when $B L=0$, and $\beta_{1}$ was the difference in CAL for each one-unit difference in BL. The model was statistically significant $(F(1,786)=1616.20$, $p<0.001)$ and explained $67 \%$ of the variance. All parameters of the model were significant $(p<0.001)$ and estimated as follows:

$$
\mathrm{CAL}=2.0 \mathrm{~mm}+1.3 \mathrm{BL}
$$

Using this model, measured radiographic $B L$ was related to measured CAL with $B L$ categories $0,1,2$ and 3 corresponding to $2.0,3.3,4.6$, and $5.9(\approx 2,3,5$ and 6$) \mathrm{mm}$ of CAL, respectively, and could be used to apply the CDC/AAP case definition. Using predicted measures of CAL to apply the CDC/AAP case definition, accurately defined $95 \%$ of cases previously defined using direct measures of CAL, with an intraclass correlation coefficient (ICC) of 0.95 .

To provide a detailed description of periodontal status, the prevalence and extent (proportion of sites and teeth affected) of threshold values ( $P D \geq 4 \mathrm{~mm}$ and $\geq 6 \mathrm{~mm}$, and $\mathrm{BL}>0 \%$ and $>10 \%$ ) were 
presented. For case definitions, mild and moderate periodontitis were combined into one category, labeled "non-severe" periodontitis. ${ }^{5,34}$ Total periodontitis was defined as the presence of either severe or non-severe periodontitis, reported as "periodontitis". BoP and plaque index (PI) were presented according to periodontitis severity and age group.

\section{Examiner reliability}

The examiners were trained under supervision of a periodontist (NO), prior to data collection to reduce measurement bias. Inter-examiner agreement in PD measurements between the 10 examiners and the periodontist (NO), was assessed at site-level. Congruency was compared to the nearest millimeter. The median ICC of agreement was 0.81 (range: $0.43-0.94)$. One examiner (GEH) performed all measurements of radiographic BL on OPGs. Test-retest agreement of site-level measurements was assessed on two occasions with two sets of duplicate examinations of 10 OPGs. In the first case, examinations performed at the beginning of the examination period were reexamined after three months, with ICC 0.78. In the second case, a second set of OPGs examined at the end of the examination period were re-examined after one week, with ICC 0.88 .

\section{Statistical analysis}

Data were analyzed using statistical software." Demographic and socioeconomic characteristics are presented as means (standard deviation, SD) or numbers (proportions) for the total study population stratified by age. Differences in background characteristics between age groups were assessed with Pearson $\chi^{2}$ test or one-way analysis of variance (ANOVA). Radiographic BL and PD are presented as means (standard error, SE) and proportions (SE) of affected sites and teeth per mouth for the total study population and by age group. PD is presented using measurements from all six sites per tooth. Tests of linear trend across age groups of BL and PD were estimated using linear regression models for continuous variables and logistic regression for binary variables. The prevalence of periodontitis is presented as proportions (SE). Overall estimates of total, severe and non-severe periodontitis were standardized to the age distribution of the 2013 Troms County population. The group with the lowest 
prevalence of periodontitis served as a referent group within each category, and the absolute difference from this group in percentage points was calculated. Differences between groups were assessed with z-tests, with a significance level set at 0.05 . Additionally, BoP and PI are presented as means (SD) for the total study population and for subpopulations stratified by severity of periodontal disease according to the CDC/AAP case definition. The Lorenz curve was created with a spreadsheet software ${ }^{\#}$ and used to describe the distribution of PD $\geq 4 \mathrm{~mm}$ in the population, ${ }^{35}$ as the cumulative proportion of total population is plotted against the cumulative proportion of $P D \geq 4 \mathrm{~mm}$. A straight diagonal line would depict perfect equality, where every person would have the same number of PD $\geq 4 \mathrm{~mm}$. The extent to which the curve sags below the straight diagonal line indicates the degree of inequality of distribution. The Gini coefficient represents the area between the line of equality (diagonal) and the Lorenz curve, calculated using the Riemann sum estimate (middle sum). The higher the Gini coefficient, the more unequal the distribution is.

\section{Results}

\section{Study population}

The mean age was 47.3 ( \pm 15.3 ) years, and $51 \%$ were women (Table 1 ). About $45 \%$ of participants resided in urban areas and $42 \%$ reported having a university level education. Approximately $20 \%$ of the examined population was categorized in the highest income group. The prevalence of diabetes was $3.8 \%$. For oral hygiene habits, the majority reported brushing their teeth $\geq 2$ times per day. Fifteen percent were current smokers. The mean number of teeth present was 25.0. Fifty-two participants $(2.7 \%)$ reported ethnicities other than Norwegian.

\section{Radiographic bone level and periodontal probing depth}

In Table 2, the prevalence and extent of radiographic BL and PD are presented by selected thresholds. Prevalence of radiographic BL spiked from the age of 35 years, reaching almost $100 \%$ in the 65-79-year-old age group. The extent of BL also increased rapidly with age. Prevalence of PD $\geq 4$ $\mathrm{mm}$ was high across all age groups. The extent of PD $\geq 4 \mathrm{~mm}$ increased with age, but to a lesser 
degree than BL. Figure 2 presents the distribution of $P D \geq 4 \mathrm{~mm}$ in the population stratified by age group. The number of sites with $\mathrm{PD} \geq 4 \mathrm{~mm}$ was unequally distributed in the population for all age groups. While more than four in five 65-79-year-olds had some sites with PD $\geq 4 \mathrm{~mm}$, the majority (80\%) of all sites with PD $\geq 4 \mathrm{~mm}$ was found in the top $20 \%$ of the age group. Disparities in the distribution of sites with PD $\geq 4 \mathrm{~mm}$ increased with decreasing age; the top $20 \%$ of 20 -34-year-olds accounted for $94 \%$ of all sites with PD $\geq 4 \mathrm{~mm}$.

\section{Prevalence and severity of periodontal disease}

The estimated prevalence and distribution of periodontitis by age and gender, as well as socioeconomic status, oral health-related behaviors and tobacco use are presented in Table 3. According to the CDC/AAP case definition, ${ }^{11}$ the prevalence of total periodontitis was estimated to be 49.5\% (SE $\pm 1.1 \%$ ), with 9.1\% severe periodontitis and $40.4 \%$ non-severe periodontitis (mild and moderate periodontitis combined). The prevalence of periodontitis increased with age; in the oldest age group, it was five times higher than in the youngest age group. Periodontitis was more prevalent among men (56.7\%) than women (42.6\%). When comparing the prevalence of periodontitis in urban and rural municipalities, there was a higher prevalence in suburban and rural municipalities than in urban areas. In addition, prevalence increased with lower education and income and current smoking habit. Prevalence of severe periodontitis was highest in the 65-79 year age group and in current smokers (Table 3).

\section{Bleeding on probing and plaque index}

Mean BoP was $30.0 \%$ and this was consistent across age groups (Table 4). BoP increased with level of severity of periodontitis, with a mean of $25.4 \%$ for persons with no periodontitis, $33.2 \%$ for persons with non-severe periodontitis and $41.7 \%$ for persons with severe periodontitis. Stratified by severity of periodontitis, BoP varied more across age groups. The mean PI was $44.2 \%$, and increased with the severity of periodontitis and age. 


\section{Discussion}

The results suggested that half of adults in the target population had periodontitis; approximately four of 10 had non-severe periodontitis, and only one of 10 had severe periodontitis. That severity and extent of the disease increased with age was expected, as periodontitis often is seen as a chronic disease and cumulative over time. ${ }^{36}$ Prevalence of periodontitis was highest among people with lower education and current smoking habit.

The majority of the study population was healthy, educated and reported making regular dental visits and practicing good oral hygiene. The participants had a high educational level; $42 \%$ had university level education compared with nationwide $35 \% .{ }^{37}$ Educational level was highest in the largest municipality, ${ }^{27}$ where the Arctic University of Norway and University Hospital of North Norway is located, contribution to the high number of persons with university level education. The proportion of persons with university level education in sub-urban and rural municipalities was equivalent to the national average. ${ }^{27}$ Smoking and diabetes had the same rates as the national averages and estimates, with $15 \%$ and $4 \%$, respectively. ${ }^{38,39}$

\section{Periodontitis in Europe and USA}

Comparing the findings in this study with previous findings in Norway is not straightforward because different measures of periodontitis have been used. The prevalence of PD $\geq 6 \mathrm{~mm}$ (Table 2) was in the range of the results from the Oslo study in comparable age groups (8\%), ${ }^{18}$ while the prevalence of $\mathrm{BL}$ was considerably higher in the present study than among 35-year-olds in Oslo in 2003 (24\%). In the study of Norwegian elderly pensioners ( $\geq 67$ years), the prevalence of $\geq 1$ tooth $P D \geq 6 \mathrm{~mm}$ was reported to be $33 \%,{ }^{19}$ consistent with the results in the current study for the same age group. Conversely, the prevalence of severe periodontitis was only half of what was found in the current study. One explanation could be the case definition used for severe periodontitis ( $\geq 3$ periodontal pockets $\geq 6 \mathrm{~mm}$ ) by Norderyd and colleagues in 2012 and possibly the partial-mouth recording (one site per tooth), which could have provided biased estimates of periodontitis. ${ }^{19,40-42}$ 
Our findings were comparable with the prevalence reported in a Swedish study: 39\% for periodontitis of any severity and $11 \%$ for severe periodontitis. ${ }^{2}$ However, a different case definition for periodontitis was used, and direct comparison should be made with caution. In comparison with studies applying the CDC/AAP case definition, the prevalence of periodontitis in this study concurred with the prevalence reported for US adults: $46 \%$ for periodontitis of any severity and $9 \%$ for severe periodontitis. ${ }^{5}$ The prevalence reported in German and Italian studies evaluating periodontitis with the CDC/AAP case definition was considerably higher. For German adults (35-44 years), prevalence of periodontitis and severe periodontitis were reported to be $71 \%$ and $17 \%$, respectively. ${ }^{4}$ For adults aged 20-75 years in Northern Italy, estimated prevalences of periodontitis and severe periodontitis was $76 \%$ and $35 \%$, respectively. ${ }^{6}$ These discrepancies between studies could partly be explained by differences in the underlying characteristics of the study populations. There was a larger proportion of current and former smokers in the German and Italian studies compared with the present study, ${ }^{4,6}$ and the proportions of people with middle and high levels of education were greater in the present study compared with other countries.

\section{Differences in periodontal health}

The present study showed differences in the population regarding the distribution of periodontitis, which was in accordance with other reported data. ${ }^{4,5,43}$ These discrepancies could be explained by differences in oral health-related behavior, in access to dental health care and norms for seeking treatment. However, in bivariate analysis, persons making annual dental visits did not have less periodontitis than persons with less frequent dental visits; rather, it was the opposite. This could be a result of neglected important aspects of prevention dentistry, under-treatment or under-diagnosis or that people categorized with yearly dental visits also include those undergoing treatment, e.g. periodontal treatment.

The most notable differences in periodontitis was across age groups, with more than $80 \%$ of persons $\geq 65$ years old affected (Table 4). Although a large number of seniors had periodontitis, the burden of PD $\geq 4 \mathrm{~mm}$ was not equally distributed in the population (Figure 2). A small proportion of 
the senior population accounted for the majority of $P D \geq 4 \mathrm{~mm}$, meaning that there was a subgroup of seniors with more extensive periodontitis. The number of natural teeth in seniors is increasing. ${ }^{44}$ Based on an estimate that every fifth person in Norway will be at least 70 years old in $2060,{ }^{45}$ it is important for dental health care services to be capable of detecting individuals with periodontitis at an early stage and for preventive measures to be implemented. Clinicians should be trained in and adopt methods that have been reported to be effective in improving oral health-related behaviors, ${ }^{46-}$ ${ }^{48}$ and the role of dental hygienists and dentists with special knowledge of prevention and oral health promotion should be emphasized in all parts of the country.

\section{Strengths and limitations}

There were some limitations to note. Only slightly more than half ( $57.3 \%$ ) of adults $\geq 65$ years old responded, which could have caused biased results for this age group. The most common reasons for not participating were health issues in combination with travel difficulties and no subjective need or interest in participating (e.g., wearing dentures). ${ }^{27}$ Additionally, more men than women $\geq 65$ years old participated, which might have resulted in overestimation of periodontitis prevalence for men.

The indirect approach to CAL by predicting CAL from BL could have led to errors in case definitions and possible underestimation of periodontitis. Variance in the ability of $B L$ to predict $C A L$ increased with increasing values of CAL. However, the use of threshold values of CAL $\geq 4$ and $\geq 6 \mathrm{~mm}$ to define cases, minimized errors of high measures of CAL. Finally, geographical disparities, including the low periodontist-to-patient ratio in Northern Norway, different living conditions, culture and attitudes towards health, should be considered when extrapolating estimates to other regions and countries.

The study also had several strengths, including the high participation rate and full-mouth examination protocol. Furthermore, to the best of our knowledge, this was the first study to apply the recommended standards for reporting chronic periodontitis, enabling future comparisons across studies and contributing to the understanding of the global burden of periodontitis. 


\section{Conclusions}

In conclusion, this study reveals a high burden of periodontitis in circumpolar communities in Norway, with half the adult population affected. Sociodemographic disparities regarding periodontitis was shown, highlighting the importance of further investigation of factors influencing periodontal health. The results from this study contributes new knowledge and will be valuable in planning dental health care and population-based preventive actions.

\section{Footnotes}

|| UNC 15, American Eagle Instruments, Inc., Missoula, MT.

I SPSS, Version 24.0, IBM, Armonk, NY.

\# Excel 2013 for Windows, Microsoft, Redmond, WA.

\section{Acknowledgements}

The authors thank all of the dental teams at the public dental clinics in Finnsnes, Harstad, Målselv, Storslett and TkNN for helping with the data collection. The TOHNN study was founded by the Troms County Council and The Norwegian Directorate of Health. The authors report no conflicts of interest related to this study. 


\section{References}

1. Hugoson A, Norderyd $\mathrm{O}$. Has the prevalence of periodontitis changed during the last 30 years? J Clin Periodontol 2008;35:338-345.

2. Hugoson A, Sjodin B, Norderyd O. Trends over 30 years, 1973-2003, in the prevalence and severity of periodontal disease. J Clin Periodontol 2008;35:405-414.

3. Bernabe E, Marcenes W. Periodontal disease and quality of life in British adults. J Clin Periodontol 2010;37:968-972.

4. Holtfreter B, Kocher T, Hoffmann T, Desvarieux M, Micheelis W. Prevalence of periodontal disease and treatment demands based on a German dental survey (DMS IV). J Clin Periodontol 2010;37:211-219.

5. Eke PI, Dye BA, Wei L, et al. Update on prevalence of periodontitis in adults in the United States: NHANES 2009 to 2012. J Periodontol 2015;86:611-622.

6. Aimetti M, Perotto S, Castiglione A, Mariani GM, Ferrarotti F, Romano F. Prevalence of periodontitis in an adult population from an urban area in North Italy: findings from a crosssectional population-based epidemiological survey. J Clin Periodontol 2015;42:622-631.

7. Kassebaum NJ, Bernabe E, Dahiya M, Bhandari B, Murray CJ, Marcenes W. Global burden of severe periodontitis in 1990-2010: a systematic review and meta-regression. J Dent Res 2014;93:1045-1053.

8. Albandar JM. Underestimation of periodontitis in NHANES surveys. J Periodontol 2011;82:337-341.

9. Borrell LN, Burt BA, Taylor GW. Prevalence and trends in periodontitis in the USA: the [corrected] NHANES, 1988 to 2000. J Dent Res 2005;84:924-930.

10. Konig J, Holtfreter B, Kocher T. Periodontal health in Europe: future trends based on treatment needs and the provision of periodontal services--position paper 1. Eur J Dent Educ 2010;14 Suppl 1:4-24.

11. Eke PI, Page RC, Wei L, Thornton-Evans G, Genco RJ. Update of the case definitions for population-based surveillance of periodontitis. J Periodontol 2012;83:1449-1454.

12. Holtfreter B, Albandar JM, Dietrich T, et al. Standards for reporting chronic periodontitis prevalence and severity in epidemiologic studies: Proposed standards from the Joint EU/USA Periodontal Epidemiology Working Group. J Clin Periodontol 2015;42:407-412.

13. United Nations. Political declaration of the high-level meeting of the General Assembly on the prevention and control of non-communicable diseases. Resolution A/66/L1. Available at: http://www.un.org/ga/search/view doc.asp?symbol=A/RES/64/265\&Lang=E. Accessed: 1 May, 2017.

14. Shanbhag S, Dahiya M, Croucher R. The impact of periodontal therapy on oral health-related quality of life in adults: a systematic review. J Clin Periodontol 2012;39:725-735.

15. Buset SL, Walter C, Friedmann A, Weiger R, Borgnakke WS, Zitzmann NU. Are periodontal diseases really silent? A systematic review of their effect on quality of life. J Clin Periodontol 2016;43:333-344. 
16. O'Dowd LK, Durham J, McCracken GI, Preshaw PM. Patients' experiences of the impact of periodontal disease. J Clin Periodontol 2010;37:334-339.

17. Norheim PW. Oral health status in a population in Northern Norway. Acta Odontol Scand 1979;37:293-300.

18. Skudutyte-Rysstad R, Eriksen HM, Hansen BF. Trends in periodontal health among 35-yearolds in Oslo, 1973-2003. J Clin Periodontol 2007;34:867-872.

19. Norderyd O, Henriksen BM, Jansson H. Periodontal disease in Norwegian old-age pensioners. Gerodontology 2012;29:4-8.

20. Statistics Norway. Health, care and social relations, survey on living conditions. Available at: https://www.ssb.no/en/helse/statistikker/helseforhold/hvert-3-aar/2016-06-20\#content. Accessed: 18 January, 2017.

21. Henriksen BM, Axell T, Laake K. Geographic differences in tooth loss and denture-wearing among the elderly in Norway. Community Dent Oral Epidemiol 2003;31:403-411.

22. Brodeur JM, Payette M, Beniger M, Charbonneau A, Olivier M, Chabot D. Periodontal diseases among Quebec adults aged 35 to 44 years. J Can Dent Assoc 2001;67:34.

23. Benigeri M, Brodeur JM, Payette M, Charbonneau A, Ismail Al. Community periodontal index of treatment needs and prevalence of periodontal conditions. J Clin Periodontol 2000;27:308312.

24. Suominen-Taipale AL. Oral health in the Finnish adult population : health 2000 survey. In: Kansanterveyslaitoksen julkaisuja. vol. 25/2008. Helsinki: National Public Health Institute, 2008.

25. Galan D, Odlum O, Brecx M. Oral health status of a group of elderly Canadian Inuit (Eskimo). Community Dent Oral Epidemiol 1993;21:53-56.

26. Skrepcinski FB, Niendorff WJ. Periodontal disease in American Indians and Alaska Natives. Journal of public health dentistry 2000;60 Suppl 1:261-266.

27. Holde GE, Oscarson N, Tillberg A, Marstrander P, Jonsson B. Methods and background characteristics of the TOHNN study: a population-based study of oral health conditions in northern Norway. Int J Circumpolar Health 2016;75:30169.

28. Holst D. Oral health equality during 30 years in Norway. Community Dent Oral Epidemiol 2008;36:326-334.

29. Holst D, Schuller AA. Equality in adults' oral health in Norway. Cohort and cross-sectional results over 33 years. Community Dent Oral Epidemiol 2011;39:488-497.

30. Adekoya SMB, M. Oral health of adults in northern Norway-A pilot study. Norwegian Journal of Epidemiology 2012;22:31-38.

31. Schei O, Waerhaug J, Lovdal A, Arno A. Alveolar bone loss as related to oral hygiene and age. J Periodontol 1959;30:7-16.

32. O'Leary TJ, Drake RB, Naylor JE. The plaque control record. J Periodontol 1972;43:38.

33. Tonetti MS, Pini Prato G, Williams RC, Cortellini P. Periodontal regeneration of human infrabony defects. III. Diagnostic strategies to detect bone gain. J Periodontol 1993;64:269277. 
34. Eke PI, Wei L, Thornton-Evans GO, et al. Risk indicators for periodontitis in US Adults: NHANES 2009 to 2012. J Periodontol 2016;87:1174-1185.

35. Lorenz MO. Methods of measuring the concentration of wealth. Publications of the American Statistical Association 1905;9:209-219.

36. Novak KF, Novak MJ. Risk Assessment. In: Newman MG, Takei H, Carranza FA, eds. Carranza's clinical periodontology. Philadelphia: W.B. Saunders Co., 2002:469-471.

37. Statistics Norway. Population's level of education. Available at: https://www.ssb.no/en/utniv. Accessed: 25 January, 2017.

38. Statistics Norway. Smoking habits. Available at: https://www.ssb.no/en/helse/statistikker/royk. Accessed: 25 January, 2017.

39. Norwegian Insitute of Public Health. Diabetes in Norway - Public health report Available at: https://www.fhi.no/en/op/public-health-report-2014/health--disease/diabetes-in-norway--public-health-/. Accessed: 25 January 2017.

40. Kingman A, Albandar JM. Methodological aspects of epidemiological studies of periodontal diseases. Periodontol 2000 2002;29:11-30.

41. Kingman A, Susin C, Albandar JM. Effect of partial recording protocols on severity estimates of periodontal disease. J Clin Periodontol 2008;35:659-667.

42. Susin C, Kingman A, Albandar JM. Effect of partial recording protocols on estimates of prevalence of periodontal disease. J Periodontol 2005;76:262-267.

43. Albandar JM. Epidemiology and risk factors of periodontal diseases. Dent Clin North Am 2005;49:517-532, v-vi.

44. Ambjørnsen E, Axéll T, Henriksen B. Do the old-age pensioners have an unexpectedly poor oral health? (In Norwegian). Nor Tannlegeforen Tid 2002;112:272-274.

45. Statistics Norway. Population projections. Available at: https://www.ssb.no/en/befolkning/statistikker/folkfram/aar/2014-06-17\#content. Accessed: 24 March, 2014.

46. Jonsson B, Ohrn K, Oscarson N, Lindberg P. An individually tailored treatment programme for improved oral hygiene: introduction of a new course of action in health education for patients with periodontitis. International journal of dental hygiene 2009;7:166-175.

47. Jonsson B, Ohrn K, Oscarson N, Lindberg P. The effectiveness of an individually tailored oral health educational programme on oral hygiene behaviour in patients with periodontal disease: a blinded randomized-controlled clinical trial (one-year follow-up). J Clin Periodontol 2009;36:1025-1034.

48. Newton JT, Asimakopoulou K. Managing oral hygiene as a risk factor for periodontal disease: a systematic review of psychological approaches to behaviour change for improved plaque control in periodontal management. J Clin Periodontol 2015;42 Suppl 16:S36-46. 


\section{Figure legends}

Figure 1. Flow chart of study participants, presented in numbers.

Figure 2. Proportional distribution of sites with PD $\geq 4 \mathrm{~mm}$ in different age groups. Each point of the curves denotes the proportion of the population (x-axis) responsible for the proportion of the total burden of PD $\geq 4 \mathrm{~mm}$ (y-axis) in respective age groups. E.g. in 65-79-year-olds the top $20 \%$ of the population accounted for $80 \%$ of the total burden of PD $\geq 4 \mathrm{~mm}$, while in 20 -34-year-olds the top $20 \%$ of the population accounted for $94 \%$ of the total burden of PD $\geq 4 \mathrm{~mm}$. 
Table 1. Characteristics of Study Participants with Periodontal Examination $(N=1,911)$ Stratified by Age and in Total.

\begin{tabular}{|c|c|c|c|c|c|c|c|}
\hline \multirow[b]{2}{*}{ Characteristics } & \multicolumn{5}{|c|}{ Age groups, years } & \multirow[b]{2}{*}{$p$ value* } & \multirow[t]{2}{*}{ Total } \\
\hline & $20-34$ & $35-44$ & $45-54$ & $55-64$ & $65-79$ & & \\
\hline Number of participants & 461 & 385 & 392 & 373 & 300 & & 1,911 \\
\hline \multicolumn{8}{|l|}{ Proportion of target } \\
\hline population, \% & 1.5 & 1.7 & 1.8 & 1.9 & 1.6 & & 1.7 \\
\hline Male gender, n (\%) & $203(44.0)$ & $187(48.6)$ & $190(48.5)$ & $194(52.0)$ & $162(54.0)$ & 0.062 & $936(49.0)$ \\
\hline Ethnicity, n (\%) & & & & & & 0.780 & \\
\hline Norwegian & 445 (96.5) & $377(98.2)$ & $379(96.7)$ & $364(97.6)$ & $292(97.7)$ & & $1,857(97.3)$ \\
\hline Sámi & $7(1.5)$ & $3(0.8)$ & $5(1.3)$ & $6(1.6)$ & $3(1.0)$ & & $24(1.3)$ \\
\hline Other & $9(2.0)$ & $4(1.0)$ & $8(2.0)$ & $3(0.8)$ & $4(1.3)$ & & $28(1.5)$ \\
\hline Education, n (\%) & & & & & & $<0.001$ & \\
\hline University level & $190(41.4)$ & $222(58.0)$ & $171(43.8)$ & $133(36.2)$ & $79(26.8)$ & & $795(42.0)$ \\
\hline High school & $245(53.4)$ & $141(36.8)$ & $168(43.1)$ & $165(45.0)$ & $107(36.3)$ & & $826(43.6)$ \\
\hline Secondary school & $24(5.2)$ & $20(5.2)$ & $51(13.1)$ & $69(18.8)$ & 109 (36.9) & & $273(14.4)$ \\
\hline \multicolumn{8}{|l|}{ Household income $\ddagger$, $n$} \\
\hline (\%) & & & & & & $<0.001$ & \\
\hline$\geq 105,499$ USD & $69(15.8)$ & $122(32.4)$ & $101(26.1)$ & $65(18.0)$ & $13(4.7)$ & & $370(20.1)$ \\
\hline $52,750-105,498$ USD & $179(41.1)$ & $194(51.5)$ & $208(53.7)$ & $214(59.3)$ & $114(41.3)$ & & $909(49.5)$ \\
\hline$<52,750$ USD & $188(43.1)$ & $61(16.2)$ & $78(20.2)$ & $82(22.7)$ & $149(54.0)$ & & $558(30.4)$ \\
\hline \multicolumn{8}{|l|}{ Demographic status, $\mathrm{n}$} \\
\hline (\%) & & & & & & $<0.001$ & \\
\hline Urban & $226(49.0)$ & $194(50.4)$ & $187(47.7)$ & $142(38.1)$ & $117(39.0)$ & & $866(45.3)$ \\
\hline Suburban & 133 (28.9) & $108(28.1)$ & $129(32.9)$ & $134(35.9)$ & $88(29.3)$ & & $592(31.0)$ \\
\hline Rural & $102(22.1)$ & $83(21.6)$ & $76(19.4)$ & $97(26.0)$ & $95(31.7)$ & & $453(23.7)$ \\
\hline \multicolumn{8}{|l|}{ Tooth brushing } \\
\hline frequency, n (\%) & & & & & & $<0.001$ & \\
\hline$\geq 2$ times/day & 314 (68.9) & $279(73.0)$ & $301(77.0)$ & $282(77.0)$ & $182(62.1)$ & & $1,358(71.9)$ \\
\hline 1 time/day & $121(26.5)$ & $92(24.1)$ & $81(20.7)$ & $77(21.0)$ & $87(29.7)$ & & $458(24.3)$ \\
\hline$<1$ time/day & $21(4.6)$ & $11(2.9)$ & $9(2.3)$ & $7(1.9)$ & $24(8.2)$ & & $72(3.8)$ \\
\hline \multicolumn{8}{|l|}{ Frequency of dental visit, } \\
\hline$n(\%)$ & & & & & & $<0.001$ & \\
\hline Yearly & 145 (31.5) & $183(48.2)$ & $232(59.2)$ & $249(67.3)$ & $196(66.2)$ & & $1,005(53.0)$ \\
\hline Every other year & $85(18.2)$ & $61(16.1)$ & $53(13.5)$ & $36(9.7)$ & $20(6.8)$ & & $255(13.4)$ \\
\hline Less often & $81(17.6)$ & $47(12.4)$ & $34(8.7)$ & $28(7.6)$ & $24(8.1)$ & & $214(11.3)$ \\
\hline \multicolumn{8}{|l|}{ Only for acute } \\
\hline problems & $149(32.4)$ & $89(23.4)$ & 73 (18.6) & $57(15.4)$ & 56 (18.9) & & $424(22.3)$ \\
\hline Smoking status, n (\%) & & & & & & 0.003 & \\
\hline Never smoker & $402(87.6)$ & $309(81.3)$ & 311 (79.7) & $291(78.4)$ & $259(86.9)$ & & $1,572(82.8)$ \\
\hline Former smoker & $10(2.2)$ & $9(2.4)$ & $6(1.5)$ & $10(2.7)$ & $8(2.7)$ & & $43(2.3)$ \\
\hline Current smoker & $47(10.2)$ & $62(16.3)$ & $73(18.7)$ & 70 (18.9) & $31(10.4)$ & & $283(14.9)$ \\
\hline
\end{tabular}


Smokeless tobacco use $\ddagger$,

$\mathrm{n}(\%)$

\begin{tabular}{lrrrrrr} 
Never user & $321(69.8)$ & $324(85.3)$ & $353(90.5)$ & $343(93.0)$ & $291(99.3)$ & $1,632(86.3)$ \\
Former user & $4(0.9)$ & $4(1.1)$ & $3(0.8)$ & $0(0)$ & $0(0)$ & $11(0.6)$ \\
Current user & $135(29.3)$ & $52(13.7)$ & $34(8.7)$ & $26(7.0)$ & $2(0.7)$ & $249(13.2)$ \\
Diabetes mellitus, n (\%) & $3(0.7)$ & $5(1.3)$ & $10(2.6)$ & $20(5.4)$ & $34(11.8)$ & $<0.001$ \\
\hline
\end{tabular}

Tooth count in dentate

(28), mean (SD)

27.2 (1.6) $26.9(1.7)$

$26.1(2.3) \quad 24.0(4.6)$

$19.1(7.0)<0.001+$

$25.0(4.7)$

Data are presented as means (standard deviation, SD) or as numbers with percentages given in parentheses.

* $P$-value for differences between groups using the $\chi^{2}$ test or one-way ANOVAt.

‡ Average household income in Norway for 2013: 85,665 USD

$\S$ Swedish type low-nitrosamine smokeless tobacco 
Table 2. Prevalence and Extent of BL and PD and Overall Mean BL and PD by Age Group and in Total.

\begin{tabular}{|c|c|c|c|c|c|c|c|}
\hline \multirow[b]{2}{*}{ Measure of periodontitis } & \multicolumn{6}{|c|}{ Age groups, years } & \multirow[t]{2}{*}{ Total } \\
\hline & $20-34$ & $35-44$ & $45-54$ & $55-64$ & $65-79$ & trend* & \\
\hline \multicolumn{8}{|l|}{ Bone loss (BL), \% (SE) } \\
\hline \multicolumn{8}{|l|}{ Prevalence } \\
\hline $\mathrm{BL}>0 \%$ & $28.0(2.1)$ & $68.1(2.4)$ & $84.7(1.8)$ & $97.1(0.9)$ & $99.3(0.5)$ & $<0.001$ & $72.4(1.0)$ \\
\hline $\mathrm{BL}>10 \%$ & $4.8(1.0)$ & $20.3(2.1)$ & $35.5(2.4)$ & $66.2(2.5)$ & $78.3(2.4)$ & $<0.001$ & $37.7(1.1)$ \\
\hline \multicolumn{8}{|l|}{ Bone loss (BL), mean (SE) } \\
\hline \multicolumn{8}{|c|}{ Proportion of sites/mouth (\%) } \\
\hline $\mathrm{BL}>0 \%$ & $1.7(0.2)$ & $7.3(0.6)$ & $18.8(1.1)$ & $38.5(1.5)$ & $52.7(1.6)$ & $<0.001$ & $21.5(0.6)$ \\
\hline $\mathrm{BL}>10 \%$ & $0.2(0.04)$ & $0.8(0.1)$ & $3.8(0.5)$ & $10.8(1.0)$ & $17.8(1.3)$ & $<0.001$ & $5.9(0.3)$ \\
\hline \multicolumn{8}{|c|}{ Proportion of teeth/mouth (\%) } \\
\hline $\mathrm{BL}>0 \%$ & $2.9(0.04)$ & $11.1(0.8)$ & $25.1(1.3)$ & $48.1(1.5)$ & $63.0(1.6)$ & $<0.001$ & $27.4(0.7)$ \\
\hline $\mathrm{BL}>10 \%$ & $0.3(0.1)$ & $1.4(0.2)$ & $5.4(0.7)$ & $14.6(1.1)$ & $23.6(1.5)$ & $<0.001$ & $8.0(0.4)$ \\
\hline Mean BL (\%) & $0.2(0.03)$ & $0.8(0.07)$ & $2.5(0.20)$ & $5.8(0.34)$ & $8.8(0.50)$ & $<0.001$ & $3.2(0.13)$ \\
\hline \multicolumn{8}{|l|}{ Probing depth (PD), \% (SE) } \\
\hline \multicolumn{8}{|l|}{ Prevalence } \\
\hline $\mathrm{PD} \geq 4 \mathrm{~mm}$ & $54.9(2.3)$ & $65.7(2.4)$ & $71.4(2.3)$ & $80.2(2.1)$ & $81.0(2.3)$ & $<0.001$ & $69.5(1.1)$ \\
\hline$P D \geq 6 \mathrm{~mm}$ & $5.9(1.1)$ & $12.7(1.7)$ & $17.6(1.9)$ & $30.6(2.4)$ & $33.0(2.7)$ & $<0.001$ & $18.7(0.9)$ \\
\hline \multicolumn{8}{|c|}{ Probing depth (PD), mean (SE) } \\
\hline \multicolumn{8}{|c|}{ Proportion of sites/mouth (\%) } \\
\hline $\mathrm{PD} \geq 4 \mathrm{~mm}$ & $2.9(0.3)$ & $4.2(0.4)$ & $6.1(0.5)$ & $9.3(0.7)$ & $10.3(0.8)$ & $<0.001$ & $6.2(0.2)$ \\
\hline$P D \geq 6 \mathrm{~mm}$ & $0.1(0.1)$ & $0.3(0.1)$ & $0.7(0.2)$ & $1.1(0.2)$ & $1.3(0.2)$ & $<0.001$ & $0.6(0.1)$ \\
\hline \multicolumn{8}{|c|}{ Proportion of teeth/mouth (\%) } \\
\hline $\mathrm{PD} \geq 4 \mathrm{~mm}$ & $10.0(0.8)$ & $14.3(1.0)$ & $18.0(1.1)$ & $25.4(1.4)$ & $27.4(1.6)$ & $<0.001$ & $18.3(0.5)$ \\
\hline$P D \geq 6 \mathrm{~mm}$ & $0.5(0.2)$ & $1.1(0.2)$ & $2.4(0.4)$ & $4.0(0.5)$ & $4.2(0.5)$ & $<0.001$ & $2.3(0.2)$ \\
\hline Mean PD (mm) & $2.0(0.02)$ & $2.1(0.02)$ & $2.1(0.02)$ & $2.2(0.03)$ & $2.3(0.04)$ & $<0.001$ & $2.1(0.01)$ \\
\hline
\end{tabular}

Values are given as means or percentages with standard error in parentheses.

Bone loss (BL) of $>0 \%$ and $>10 \%$ relating to degree of clinical attachment loss ( $A L$ ) $\geq 3$ and $\geq 5 \mathrm{~mm}$, respectively

$* P$-value for linear trend across age groups 
Table 3. Distribution of Participants Classified According to the CDC/AAP Case Definition by Sociodemographic, Behavioural and Co-morbidity Variables; Proportions

\begin{tabular}{|c|c|c|c|c|c|c|c|c|c|c|}
\hline \multirow[b]{3}{*}{ Characteristics } & \multirow[b]{3}{*}{$\mathrm{n}$} & \multicolumn{9}{|c|}{ Periodontitis (CDC/AAP Case Definition) $^{11}$} \\
\hline & & \multicolumn{3}{|c|}{ Non-severe } & \multicolumn{3}{|c|}{ Severe } & \multicolumn{3}{|l|}{ Total } \\
\hline & & $\%$ & (SE) & $\begin{array}{l}\text { Absolute } \\
\text { difference } \\
\text { (pp) }\end{array}$ & $\%$ & (SE) & $\begin{array}{l}\text { Absolute } \\
\text { difference } \\
\text { (pp) }\end{array}$ & $\%$ & $(\mathrm{SE})$ & $\begin{array}{l}\text { Absolute } \\
\text { difference } \\
\text { (pp) }\end{array}$ \\
\hline Total & 1,911 & 40.4 & (1.1) & & 9.1 & $(0.7)$ & & 49.5 & $(1.1)$ & \\
\hline $\begin{array}{l}\text { Total, Age } \\
\text { standardized* }\end{array}$ & & 39.2 & (1.1) & & 8.8 & $(0.6)$ & & 48.2 & $(1.1)$ & \\
\hline \multicolumn{11}{|l|}{ Age group (yrs.) } \\
\hline $20-34$ & 461 & 15.8 & (1.7) & Ref.a & 0.2 & $(0.2)$ & Ref.a & 16.1 & $(1.7)$ & Ref.a \\
\hline $35-44$ & 385 & 33.0 & (2.4) & $17.2_{b}$ & 1.6 & $(0.6)$ & $1.4_{a}$ & 34.6 & $(2.4)$ & $18.5_{b}$ \\
\hline $45-54$ & 392 & 46.4 & (2.5) & $30.6_{c}$ & 7.4 & (1.3) & $7.2_{b}$ & 53.8 & (2.5) & $37.7_{c}$ \\
\hline $54-64$ & 373 & 57.9 & (2.6) & $42.1_{d}$ & 18.0 & (2.0) & $17.8_{c}$ & 75.9 & (2.2) & $59.8_{d}$ \\
\hline $65-79$ & 300 & 57.7 & (2.9) & $41.9_{d}$ & 23.7 & (2.5) & $23.5_{c}$ & 81.3 & (2.3) & $65.2_{d}$ \\
\hline \multicolumn{11}{|l|}{ Gender } \\
\hline Female & 975 & 35.7 & (1.5) & Ref.a & 6.9 & $(0.8)$ & Ref.a & 42.6 & (1.6) & Ref.a \\
\hline Male & 936 & 45.2 & (1.6) & $9.5 \mathrm{~b}$ & 11.4 & (1.0) & $4.5_{b}$ & 56.7 & (1.6) & $14.1_{b}$ \\
\hline \multicolumn{11}{|l|}{ Ethnicity } \\
\hline Norwegian & 1,857 & 40.3 & (1.1) & $7.0_{a}$ & 9.0 & $(0.7)$ & $4.8 \mathrm{a}$ & 49.4 & $(1.2)$ & $11.9 \mathrm{a}$ \\
\hline & & & & & & & & & $(10$. & \\
\hline Sámi & 24 & 33.3 & (9.8) & Ref.a & 4.2 & $(4.2)$ & Ref.a & 37.5 & 1) & Ref.a \\
\hline Other & 28 & 46.4 & (9.6) & $13.1_{\mathrm{a}}$ & 14.3 & (6.7) & $10.1_{\mathrm{a}}$ & 60.7 & (9.4) & $23.2 \mathrm{a}$ \\
\hline \multicolumn{11}{|l|}{ Education } \\
\hline University & 795 & 35.2 & $(0.7)$ & Ref.a & 4.7 & $(0.7)$ & Ref.a & 39.9 & (1.7) & Ref.a \\
\hline High School & 826 & 41.8 & (1.1) & $8.3_{b}$ & 10.4 & (1.1) & $5.7_{\mathrm{b}}$ & 52.2 & (1.7) & $12.3_{b}$ \\
\hline \multicolumn{11}{|l|}{ Secondary } \\
\hline School & 273 & 50.6 & (2.3) & $6.2_{c}$ & 17.6 & (2.3) & $12.9_{\mathrm{c}}$ & 68.1 & (2.8) & $28.2_{c}$ \\
\hline \multicolumn{11}{|c|}{ Annual household income ${ }^{\dagger}$} \\
\hline \multicolumn{11}{|l|}{$\geq 105,499$} \\
\hline USD & 370 & 34.3 & $(2.5)$ & Ref.a & 4.6 & (1.1) & Ref.a & 38.9 & $(2.5)$ & Ref.a \\
\hline
\end{tabular}


52,750-

$\begin{array}{llllllllllll}105,498 \text { USD } & 909 & 42.6 & (1.6) & 8.3_{\mathrm{b}} & 8.1 & (0.9) & 3.5_{\mathrm{a}} & 50.7 & (1.7) & 11.8_{\mathrm{b}} \\ <52,750 \text { USD } & 558 & 40.5 & (2.1) & 6.2_{\mathrm{a}, \mathrm{b}} & 14.0 & (1.5) & 9.4_{\mathrm{b}} & 54.5 & (2.1) & 15.6_{\mathrm{b}}\end{array}$

Demographic status

$\begin{array}{lcccccccccc}\text { Urban } & 866 & 34.0 & (1.6) & \text { Ref.a }_{\mathrm{a}} & 8.0 & (0.9) & \text { Ref.a } & 41.9 & (1.7) & \text { Ref.a } \\ \text { Suburban } & 592 & 46.1 & (2.1) & 12.1_{\mathrm{b}} & 10.3 & (1.3) & 2.3_{\mathrm{a}} & 56.4 & (2.0) & 14.5_{\mathrm{b}} \\ \text { Rural } & 453 & 45.0 & (2.3) & 11.0_{\mathrm{b}} & 9.7 & (1.4) & 1.7_{\mathrm{a}} & 54.8 & (2.3) & 12.9_{\mathrm{b}}\end{array}$

Frequency of dental visits

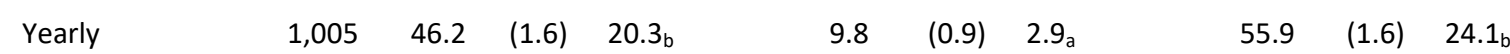

Every other

\begin{tabular}{|c|c|c|c|c|c|c|c|c|c|c|}
\hline year & 255 & 25.9 & (2.7) & Ref.a & 6.9 & (1.5) & Ref.a $_{\text {a }}$ & 31.8 & (2.9) & Ref.a \\
\hline Less often & 214 & 29.4 & (3.1) & $3.5 \mathrm{a}$ & 8.9 & (1.9) & $2.0_{a}$ & 38.3 & (3.3) & $6.5 a$ \\
\hline \multicolumn{11}{|l|}{ Only for } \\
\hline acute problems & 424 & 40.6 & (2.4) & $11.2 \mathrm{~b}$ & 9.7 & (1.4) & $2.8 \mathrm{a}$ & 50.2 & (2.4) & $18.4_{b}$ \\
\hline \multicolumn{11}{|l|}{ Smoking status } \\
\hline Never smoker & 1,572 & 37.9 & (1.2) & Ref.a & 7.4 & $(0.7)$ & Ref.a & 45.4 & (1.3) & Ref.a \\
\hline \multicolumn{11}{|l|}{ Former } \\
\hline smoker & 43 & 46.5 & (7.7) & $8.6_{a, b}$ & 11.6 & (4.9) & $4.2_{a, b}$ & 58.1 & (7.6) & $12.7_{\mathrm{a}, \mathrm{b}}$ \\
\hline \multicolumn{11}{|l|}{ Current } \\
\hline smoker & 283 & 51.6 & (3.0) & $13.7_{\mathrm{b}}$ & 18.4 & (2.3) & $11.0_{b}$ & 70.0 & (2.7) & $24.6_{b}$ \\
\hline
\end{tabular}

Smokeless tobacco use $¥$

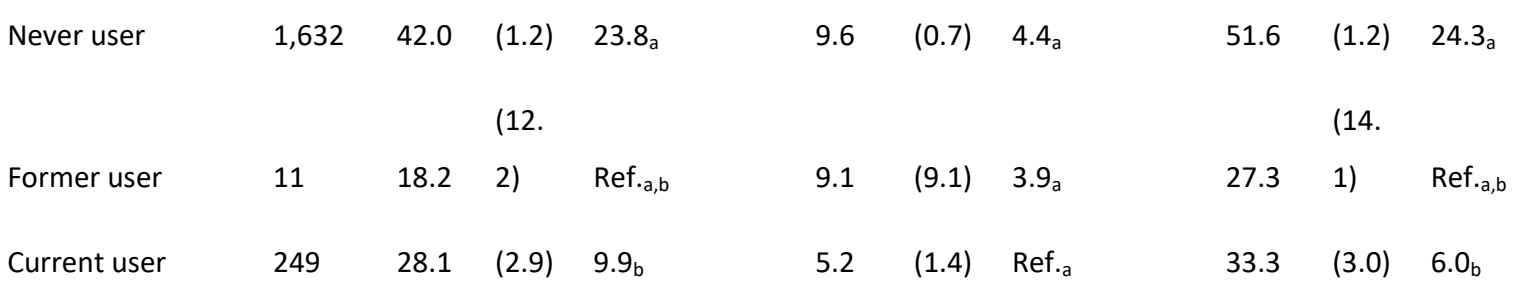

Differences between groups were assessed with z-test. Different subscript letters denotes significant differences in periodontitis prevalence between characteristics at the 0.05 level.

* Standardized to age distribution of the 2013 Troms County population.

+ Average household income in Norway for 2013: 85,665 USD

¥ Swedish type low-nitrosamine smokeless tobacco 
Table 4. Bleeding on Probing (BoP) and Plaque Score by Severity of Periodontitis Stratified by Age Group and in Total.

\begin{tabular}{|c|c|c|c|c|c|c|}
\hline \multirow{2}{*}{$\begin{array}{l}\text { Measures of gingival } \\
\text { inflammation and dental }\end{array}$} & \multicolumn{5}{|c|}{ Age, years } & \multirow{3}{*}{$\begin{array}{l}\text { Total } \\
\text { Mean (SD) }\end{array}$} \\
\hline & \multirow{2}{*}{ Mean (SD) } & \multirow{2}{*}{$\begin{array}{l}35-44 \\
\text { Mean (SD) }\end{array}$} & \multirow{2}{*}{$\begin{array}{l}45-54 \\
\text { Mean (SD) }\end{array}$} & \multirow{2}{*}{$\begin{array}{l}55-64 \\
\text { Mean (SD) }\end{array}$} & \multirow{2}{*}{$\begin{array}{l}65-79 \\
\text { Mean (SD) }\end{array}$} & \\
\hline plaque & & & & & & \\
\hline Mean BoP (\%) & $31.9(18.3)$ & $27.2(16.2)$ & $28.6(16.7)$ & $30.3(20.1)$ & $32.4(21.6)$ & $30.0(18.6)$ \\
\hline No periodontitis & $29.4(16.6)$ & $23.2(13.9)$ & $22.7(13.3)$ & $20.6(13.9)$ & $23.2(21.1)$ & $25.4(15.7)$ \\
\hline Non-severe periodontitis & $45.0(21.2)$ & $34.8(17.3)$ & $32.0(17.4)$ & $31.2(20.1)$ & $31.0(20.1)$ & $33.2(18.8)$ \\
\hline Severe periodontitis & - & $30.8(25.0)$ & $43.7(16.4)$ & $40.5(21.1)$ & $43.0(21.5)$ & $41.7(20.6)$ \\
\hline Total periodontitis & $44.8(21.1)$ & $34.6(17.6)$ & $33.6(17.7)$ & $33.4(20.7)$ & $34.5(21.2)$ & $34.8(20.0)$ \\
\hline Mean plaque score (\%) & $45.2(22.9)$ & $40.0(21.0)$ & $42.6(21.5)$ & $44.3(22.4)$ & $49.7(23.4)$ & $44.2(22.4)$ \\
\hline No periodontitis & $43.4(22.5)$ & $38.4(21.2)$ & $39.0(19.9)$ & $38.7(21.2)$ & $45.7(25.3)$ & $40.9(21.8)$ \\
\hline Non-severe periodontitis & $54.5(22.7)$ & $43.7(20.3)$ & $44.6(22.2)$ & $45.2(21.6)$ & $47.5(22.1)$ & $46.2(21.9)$ \\
\hline Severe periodontitis & - & $31.3(19.0)$ & $51.6(23.3)$ & $49.1(25.0)$ & $58.2(23.1)$ & $52.7(24.2)$ \\
\hline Total periodontitis & $54.6(22.6)$ & $43.1(20.3)$ & $45.6(22.4)$ & $46.1(22.5)$ & $50.6(22.9)$ & $47.4(22.5)$ \\
\hline
\end{tabular}




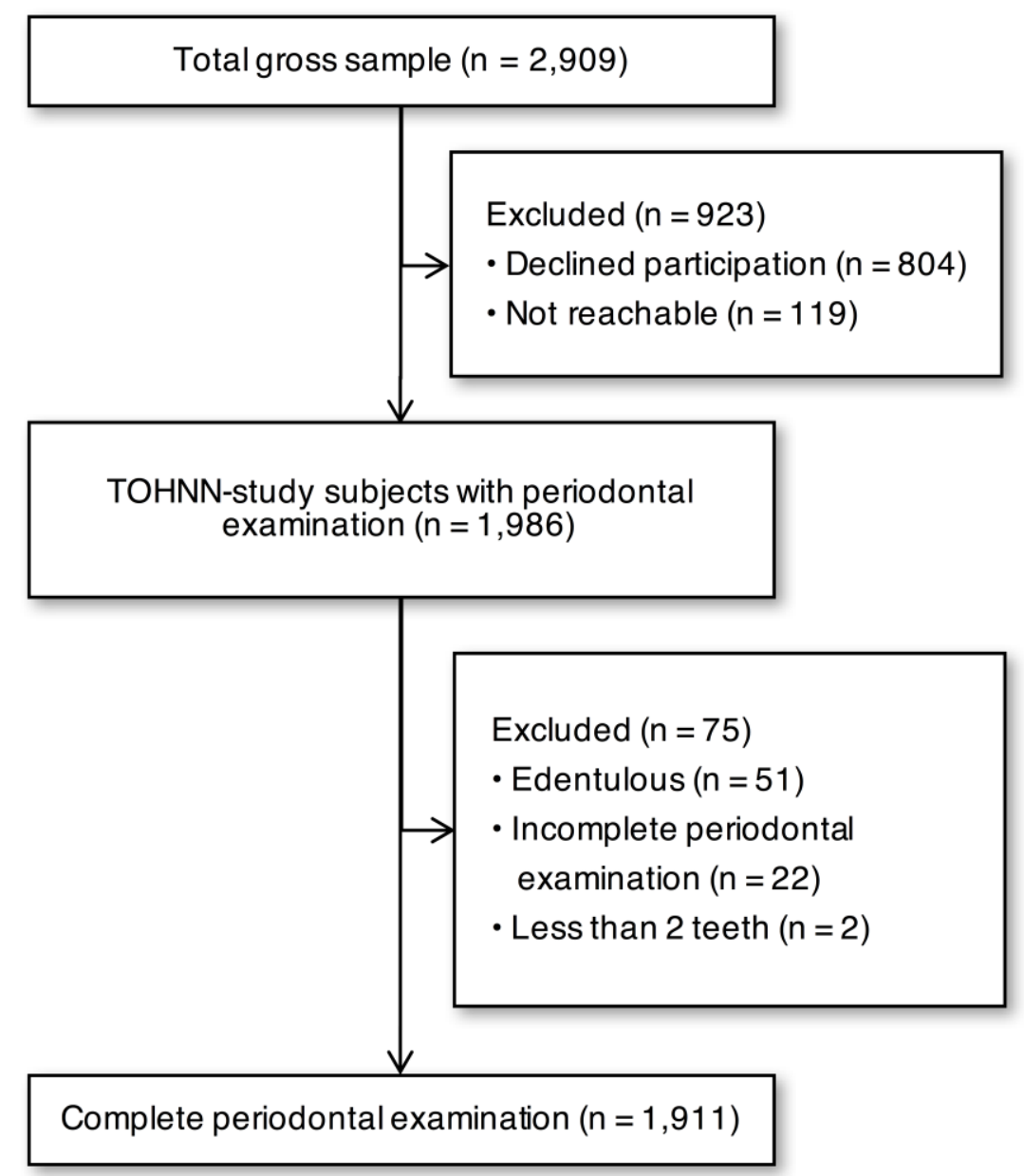

Figure 1. Flow chart of study participants, presented in numbers. 


\section{Lorenz curve}

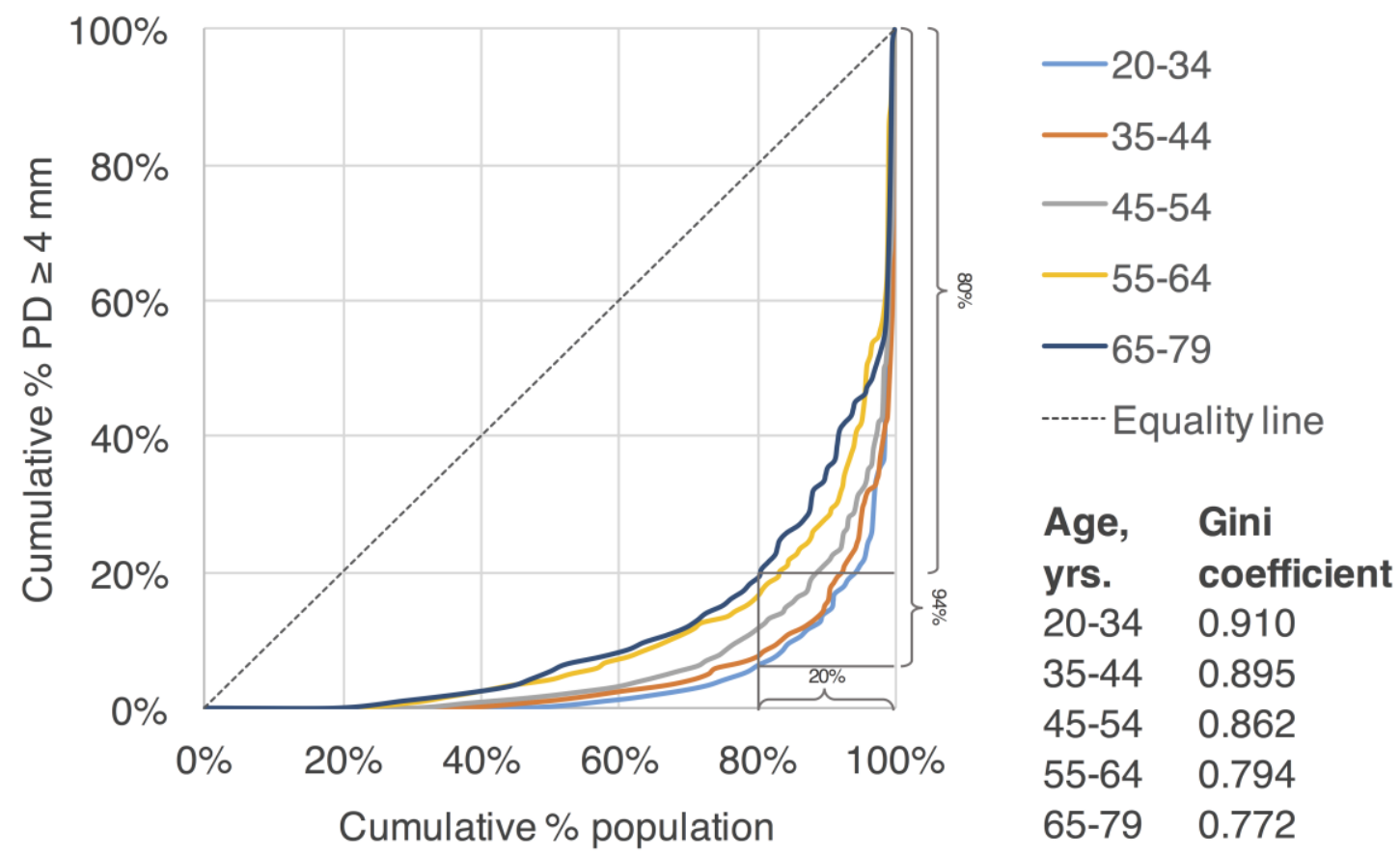

Figure 2. Proportional distribution of sites with $P D \geq 4 \mathrm{~mm}$ in different age groups. Each point of the curves denotes the proportion of the population ( $x$-axis) responsible for the proportion of the total burden of $P D \geq 4 \mathrm{~mm}$ ( $y$-axis) in respective age groups. E.g. in 65-79-year-olds the top $20 \%$ of the population accounted for $80 \%$ of the total burden of PD $\geq 4 \mathrm{~mm}$, while in 20-34-year-olds the top $20 \%$ of the population accounted for $94 \%$ of the total burden of PD $\geq 4 \mathrm{~mm}$. 